\title{
New Media and Conflict Transformation in Sri Lanka
}

\author{
Sanjana Hattotuwa
}

Abstract Can information and communication technologies (ICTs) help transform violent conflict and strengthen democracy? Can they strengthen human security when the language of hate, pervasive violence, cultures of impunity and illiberal regimes have a vice grip on polity and society? The potential of new media to transform the policies and practices of illiberal democracy is explored in this article, with special reference to Sri Lanka. Even in the terrains of violent conflict, state censorship and repression, there are spaces for democratic dialogue and citizen action mediated through the internet, the web and increasingly, mobile phones. The article flags Groundviews, Sri Lanka's first citizen journalism site, as an example of how web media can foster information-sharing and democratic dialogue in contexts of insecurity, state repression and conflict.

\section{Context}

The current situation in Sri Lanka is one in which hostilities creating a humanitarian and human rights crisis show every sign of intensifying. According to local and international press freedom groups, 14 media workers have been killed since 2005, seven have been abducted and 25 have been forced to leave Sri Lanka. There are disturbing reports of torture and psychological abuse of journalists detained by police. Instead of investigating and preventing attacks against journalists, the police themselves have abducted journalists. Several journalists live in fear for their lives, being forced to bunker in safe houses. Many have been named and shamed by the Ministry of Defence website as traitors and enemies of the state. The Defence Secretary and brother of the President Gotabaya Rajapakse, named by 'Reporters Without Borders' (RSF) as a media predator, has threatened senior journalists and editors with complete impunity. On 8 January 2009, the Editor-in-Chief of the Sunday Leader and one of Sri Lanka's best-known journalists,

Lasantha Wickremetunge, was brutally assassinated en route to work. So far no group has claimed responsibility. In a powerful editorial published posthumously, Lasantha asserts 'When finally I am killed, it will be the government that kills me.'
The question then is the following: Can information and communication technologies (ICTs) help transform violent conflict and strengthen democracy? It certainly has the potential and a robust pedigree. Stafford Beer's socialist information and communications network - Cybersyn - in Allende's Chile ${ }^{2}$ and the use of computers and modems in Operation Vula, the ANC's underground communications network against apartheid, ${ }^{3}$ are two cogent examples. New media - media that uses ICTs to produce, archive and disseminate information and knowledge - follows in a similar vein today. Yet can it meaningfully strengthen human security when a language of hate, pervasive violence, a culture of impunity and an illiberal regime has a vice-like grip on polity and society?

Through the specific example of Sri Lanka, this article explores the challenges of promoting new media, internet and web initiatives to support and strengthen democracy, human rights, human security and good governance.

\section{ICTs: help or hindrance?}

Many examples from countries with repressive regimes suggest that even when civil society and the Fourth Estate are co-opted or co-owed, new media play a vital role in strengthening human 
security, rights and democracy. ${ }^{4}$ On the other hand, illiberal regimes also use new media and ICTs for their own parochial ends and propaganda and actively impede their use by civil society. ${ }^{5}$ The recent cases of Egypt ${ }^{6}$ and Myanmar ${ }^{7}$ demonstrate the power of authoritarian regimes to clamp down on prodemocracy communications as well as jail, torture and kill civil rights activists, including bloggers. While the strongest and most open voices of dissent within repressive regimes are now found in new media, ${ }^{8}$ some argue that the latter are still too diffuse and exceptional to effectively strengthen democratic institutions and processes.

This article suggests that the new media and the social and political movements they support, can play a creative role in protecting and strengthening democratic governance by exposing to public scrutiny those responsible for the breakdown in democratic governance and for human rights abuses in ways that other media cannot. They are able to create a permanent record that can be contested but is almost impossible to erase or block.

\section{As the Berkman Center for Internet and Society} recently notes ${ }^{9}$ with regard to Iran:

Given the repressive media environment ... blogs may represent the most open public communications platform for political discourse. The peer-to-peer architecture of the blogosphere is more resistant to capture or control by the state than the older, hub and spoke architecture of the mass media model.

This mirrors the conditions in many other countries with similar regimes. New media are mobile, decentralised, two-way, adaptive, resilient and pervasive with content in the swabhasha (vernacular) as well as English. Web and internet access are no longer tethered to wires. Myriad technologies to bear witness, produce and disseminate information have exponentially increased in number, expanded in footprint and declined in cost. Citizens with mobile phones are redefining our understanding of journalists and journalism. ${ }^{10}$ Shut or block one website, a dozen others spring up - many with information on how to by-pass the censorship. Jail a blogger and many more cover the same events and processes with more vigour and scrutiny. Attempt to cull an entire village and the world is witness, thanks to initiatives, such as Amnesty's Eyes on Darfur. ${ }^{11}$ There is now talk of a 'mobile democracy' and 'm-government'. In the Philippines, large-scale demonstrations organised via mobile phones and text messaging (SMS) were a major factor in forcing President Joseph Estrada to resign, thus bringing about change without large-scale violence. ${ }^{12}$ From Zimbabwe ${ }^{13}$ and Kenya ${ }^{14}$ to China and Kuwait, ${ }^{15}$ from electoral processes and women's suffrage to the voicing of dissent against oppression, new media are revolutionising our approach to and understanding of political and social activism.

There are important market and technological factors propelling the growing influence of new media in South Asia. The region shows the highest growth for mobile phone subscribers in the Asia-Pacific. Sri Lanka, in particular, already has more mobile than fixed line subscribers including significant mobile phone ownership and use among the lowest economic groups, a vast and expanding wireless broadband footprint, low costs of internet access and text messaging, low prices of new mobile devices (including the latest third generation handsets), a thriving black market for them, significant increases in broadband connectivity (wired and wireless) and a healthy growth in PC sales.

Yet ICTs by themselves do not suffice to strengthen civic consciousness. Commercial and personal promotion and use of new media abound, but leveraging them for political and social activism is another matter. This is linked to the phenomenon that in Sri Lanka at least, voters often make poor citizens. The exercise of one's franchise at elections is all that most see as their contribution to the mechanisms of democratic governance. The potential of new media to make transparent and to hold accountable is simply lost to those who do not see the need to actively participate in the change that they all acknowledge, privately, is necessary and urgent.

A central feature of internet and new media is that it is a uniquely open two-way communicative architecture. Traditional communications media, such as television and radio, fail to enable full democratic participation due to lack of two-way communication. People feel more connected when they are able to participate in dialogue, 
instead of being idle recipients of information. The internet's structure allows for a diversity of views and exchange of information that is impossible in any other communications medium. The key to this is the decentralisation of information. No source has near exclusive control on the diffusion of information, as is the case in television and radio. Indeed technology itself redefines control. A mobile phone in the hands of a citizen subverts the blanket censorship of governments. A blog is a powerful medium through which the ground realities of conflict can be communicated to counter propaganda of the antagonists. Mobile phones with photographic capabilities can monitor ground conditions and in real-time generate images that influence key policy decisions.

But new media and citizen journalism are also not to be confused with traditional e-government initiatives. The emphasis of new media is on information produced by citizens for their own benefit - empowerment from within, as opposed to empowerment facilitated by the largesse of a ruling elite. While many e-government initiatives seek to open up information within government to citizens, new media works the other way, promoting citizen-driven content to a larger audience that includes government.

\section{Citizen journalism}

New technologies are changing the manner in which we gather, store, disseminate, consume and comment on news. The experience after the tsunami in Sri Lanka and the subsequent design of ICTs for humanitarian aid suggests that ordinary citizens can play a pivotal role in facilitating the flow of information in relief and conflict management. Professional photographers still take celebrated images but now have to compete with citizens with digital cameras in their mobile phones who are often the first to arrive, or are already present, at the scene. The first images of the London bombings (7 July 2006) were not from the broadcast quality video cameras of television networks. They were grainy, jittery images taken from mobile phones by citizens, many of whom were victims of the bombings and shown repeatedly on the BBC as well as other news networks globally.

Citizen journalism not only strengthens democracy through the dissemination of accurate and wide-ranging information as interpreted by citizens, it can also play a significant role in helping to mitigate violence. With new web-based technologies, citizens in Sri Lanka who have been effectively cut off from mainstream media have found new ways of expressing their concerns and ideas for conflict transformation. In contrast to mainstream media the conversations of this new age of citizen journalism are raw, visceral, impatient, irreverent, pithy and provocative. In Sri Lanka, they still largely take place in English and are limited mostly to urban centres. The potential of citizen journalism, however, is that in giving a foundation for all citizens - literate, illiterate, male and female, of all ethnicities, castes, class and religion - to express themselves freely, a wider process of conflict transformation can be initiated. The web is littered with examples on how text messages helped in the immediate aftermath of the tsunami in Indonesia and Sri Lanka. ${ }^{16}$ A crucial lesson was that since SMS is more resilient to destruction than telecomms infrastructure,${ }^{17}$ it can be the foundation for early warning system ${ }^{18}$ and a key alerting tool for communities at risk..$^{19}$

\section{Bearing witness through new media and citizen journalism}

Gitizen journalists are playing a major role in reporting deaths, the humanitarian fallout and hidden social costs of violent conflict, often glossed over or sensationalised by traditional media. The Human Rights Video Hub, ${ }^{20}$ run by WITNESS and Global Voices, is a powerful example. Another is how Nepali citizens used blogs to restore democracy from the disastrous rule of the monarchy that led to hundreds of deaths and gross human rights abuses. ${ }^{21}$ Such initiatives - simple yet effective - can help strengthen accountability, expose corruption and increase the responsiveness of governments to disasters. Mainstream news organisations are taking note - today, citizens across the world are actively encouraged to submit their 'palm-grown' content through dedicated portals on Reuters, AP, BBC, GNN, Al-Jazeera and many other major networks. ${ }^{22}$ Citizens using mobile devices capture much of the real-time footage coming from disasters broadcast or published on these networks. The growth of high-speed internet access means it is now possible to stream video in real time from many places in the world. This opens up the potential for new perspectives and insights into disasters - instead of one television 
crew, we now have thousands, all of them recording, bearing witness and publishing.

New media have also given rise to new ways of visualising disasters - activists now use tools such as Google Earth to highlight the enormity of human tragedy in places such as Darfur..$^{23}$ The emergence of Sri Lankan bloggers on the blogosphere is also a form of citizen journalism, as events are analysed and information disseminated from the public. For example, the analysis of events from popular bloggers like Deane's Dimension, ${ }^{24}$ Indi $^{25}$ and Dinidu De Alwis ${ }^{26}$ to name a few, has become a daily staple for many involved and tuning into the blogosphere The blog aggregator, Kottu.org, has a vast collection of Sri Lankan blogs which addresses political, economic, entertainment, security and technology topics and thus has created a public forum for the collection, reinterpretation and deconstruction of news. While bloggers are not always well informed and are often dogmatic, their vibrant and spirited discussion narrows the democratic deficit. This is particularly evident in sites such as Beyond Borders $^{27}$ and In Mutiny, ${ }^{28}$ featuring high-quality (English) content and debate, by youth, for youth.

Kottu, for example, features daily rants on theatre, art, poetry, IT, higher studies, puberty, pre-puberty blues, post-puberty blues, love, lack of love, social revolutions, peace, media, democracy, fascism, liberty, religion, music, earrings, tattoos, books, reviews and a huge array of photos from Flickr that capture moments, both private and public, of the varied lives of bloggers. Blogs like 'Dare to be Different' (run by a politician) ${ }^{29}$ jostle for attention with the 'Voices in My Head'.$^{30}$ From personal rants on the top ten extremists in Sri Lanka ${ }^{31}$ to more thoughtful analyses of Sri Lanka's socio-political dynamics, ${ }^{32}$ Kottu's collective voices offer far more food for thought than most mainstream media today. The voices are overwhelmingly young, vibrant and passionate. As Electra ${ }^{33}$ a regular and one of the more eloquent bloggers in Sri Lanka points out:

... but for what it's worth, our opinions need to be out there, reaching out to a community larger than that which has access to and interest in the Sri Lankan blogosphere. More people need to see this. More people need to hear us.

\section{Groundviews: A case study}

In order to open spaces for conflict transformation in Sri Lanka simply not available in other media, Groundviews

(www.groundviews.org) was launched in December 2006 as the first tri-lingual citizen journalism initiative in Sri Lanka. It remains the only such initiative. In December 2007, the site was awarded an Award of Excellence in New Communications from the Society for New Communications Research (SNCR). Content from Groundviews is regularly featured on other news aggregation sites as well as media reports: 'For ongoing analysis of the conflict, the citizen journalism site groundviews.org provides interesting and often tragic reporting', says 'Freedom House' on its blog. The site is the only citizen journalism website in Sri Lanka to be directly indexed on Google News (http://news.google.com) and ranked number one on Google itself by keyword. Articles on the site are regularly republished in other local media, including media websites such as InfoLanka News, Tamil Canadian and Tamilnet..$^{34}$ The site features stories that are vital pegs of hope, diversity and coexistence. Ordinary citizens, weary of violence, write them. Artists, human rights and media activists, academics, young bloggers and thinkers - none with any journalism training, write them. Groundviews is a repository of content and debate that is sorely lacking in the country's mainstream media.

However, CPA is cognisant that deeply entrenched cultures of secrecy as well as anxiety and fear profoundly influence the creation and dissemination of new media. An enduring challenge has been to seek leverage and experiment with new media within violent conflict and a rapidly eroding human rights context. Analysis of the narratives disseminated by Groundviewes suggests many perspectives of those affected by the conflict and living in the embattled North and East find expression and engagement on the site. A comparison with reportage in mainstream print media since Groundviews was launched sharply highlights the contrast in the content published. The traditional Fourth Estate, operating under high levels of state and self-censorship, has largely failed to articulate the voices of those fearful of both war and the lack of any meaningful steps taken to foster peace. 
A metric that is particularly revealing of the twoway nature of communications on Groundviews is the number of comments received on the site to all its posts - over 3,387 by 1,812 unique authors (at the time of writing). Indeed, some of these comments have been as incisive as the original posts to which they were responding. Having set out to humanise the conflict, Groundviews evolved into a site for interrogation, contestation and civil debate. It is unique in this respect even today - two years after its launch. Furthermore, even its openness to those diffusing majoritarian, state-centred conceptions of national security and democracy, provides useful markers of the significant challenges facing the country.

Yet Groundviewes does not and cannot replace traditional media or courageous individuals in civil society who stand up, when few dare to, against the egregious violations of human rights and the erosion of human security. We see Groundviewes as a force multiplier, able to strengthen the work of the Centre for Policy Alternatives (CPA) and other civil society groups. The increasing visibility of the site and its content creates its own security concerns for those associated with it and thus for its sustainability. The technology employed on the site is itself a line of defence - maintained to a high degree of resilience, redundancy and easily replicated in case of attempts to block it, shut it down or hack into it. No efforts are foolproof, but they guarantee that such attempts will not go unnoticed by the international community. Visibility, in this sense, is its own deterrent to attacks. Those who provide the content are also protected by anonymity or in most cases an identity only known to the Editor of the site. ${ }^{35}$

Groundviewes also needs to be located in the larger framework of new media growth in Sri Lanka. Swabhasha (vernacular) blogging has grown in the past two years as well as English language blogging. The geographical footprint of bloggers has widened and now extends to non-urban areas and non-elite groups. Yet, Groundviews is unique among web initiatives in (or on) Sri Lanka, in that it is a moderated site ${ }^{36}$ with site content submission guidelines that clearly note what is permissible on the site and the tone of discussion that will be encouraged. These guidelines, sui generis in the Sri Lankan blogosphere, have inspired others to follow suit and have, over time, become a de facto standard for high-quality citizen journalism in Sri Lanka incorporating principles and standards of integrity, accountability, equality, justice and courageous reporting. ${ }^{37}$

\section{Challenges}

Merely because most of us have access to a hundred times more content on conflict and disasters than before does not guarantee that we get any closer to understanding or responding adequately to them. Information overload is a real problem, as is the subjectivity of citizens, who only capture what they feel is important and often ignore aspects of a disaster that lie beyond their own comfort zones and prejudices. There is still no widely accepted standard for citizen journalists, although organisations such as the Centre for Citizen Media are actively working towards such standards. ${ }^{38}$ Not all citizens, even when they can do so and have access to digital devices, record disasters or human rights abuses - especially when their own security could be compromised for doing so. Governments can clamp down on citizen journalism. For example, the French Constitutional Council approved a law in early 2007 that criminalises the filming or broadcasting of acts of violence by anyone other than professional journalists. The law could lead to the imprisonment of eyewitnesses who film acts of police violence or operators of websites publishing the images. ${ }^{39}$

ICTs can also merely serve to strengthen hierarchies and bureaucracy that impede accountability and responsive aid delivery. In Sri Lanka, the significant deterioration of democracy in 2006-8 has resulted in a country where anxiety and fear overwhelm a sense of civic duty to bear witness to so much of what is wrong. No amount of mobile phones and PGs is going to magically erase this deep-rooted fear of speaking one's mind.

Citizen journalism can fall by the wayside as a fad if it does not foster measurable and tangible change for citizens facing the brunt of violence and conflict. The conversations can all too easily become trivial and silly as well as racist and deeply divisive. It cannot be assumed that communication automatically brings with it greater understanding, and it may well be the case that terrorists (and sections of the state deeply disinterested in peace) mould the basic technologies and frameworks of citizens journalism to spread hate and violence. 
New media may foster new perspectives, but the old problem of dealing with an intolerant and violent state does not simply vanish by the mere introduction of ICTs. For example, although censorship of media and cultural production in Sri Lanka is not new, ${ }^{40}$ the Rajapakse regime took it a step further recently when it recently promulgated a new set of regulations through a gazette notification, called the Private Television

Broadcasting Station Regulations. The broad and illdefined regulations, in parts copied and pasted verbatim from Indian Cable TV and IP TV regulations, further undermining independent media in Sri Lanka. On 14 November 2008, the Supreme Court, issuing a stay order suspending the operation of these regulations, ${ }^{41}$ granted a case lodged by the Sri Lanka Working Journalists Association and others who opposed them as an affront to freedom of expression. The case is to be heard on 26 January 2009. The proposed regulations pose significant challenges to all bloggers in Sri Lanka, since they seek to hold accountable all internet service providers (ISPs) for the qualitative nature of the content transmitted, accessed and produced.$^{42}$ There are other generic challenges to democracy and human rights promotion through new media and citizen journalism. Among them are: ${ }^{43}$

- Most donors and funders do not have any clear idea on how to best support new media to strengthen democracy within conflict or in post-conflict scenarios

- There are few Monitoring and Evaluation $(\mathrm{M} \& \mathrm{E})$ tools capable of measuring the impact of social/new media

- Few acknowledge that initial designs and implementations of new media/citizen journalism initiatives may initially fail but be vital to generate debate, discussion and interest in new media. Donors tend to write off entire initiatives and projects because they do not show the results promised or desired in the short term

New media producers often disregard the wider cultural, economic and political repercussions of the content they create. This has serious implications for local content producers, but few in Sri Lanka are aware of the risks involved in publishing 'inflammable' content online as independent web media producers. ${ }^{44}$

In Sri Lanka, the challenges to new media, internet and web activism continue to grow along with the repression of mainstream/traditional media. Given their capacity to covertly monitor, curtail and block communications at the whim of the regime, ISPs in Sri Lanka must be held up to public scrutiny. Their policies and practices need to be explicit on how they would handle extraordinary requests from the government to monitor communications, especially by nongovernmental organisations (NGOs) and human rights activists known for their criticism of the regime. The lack of enabling Right to Information legislation in Sri Lanka severely hampers consumer awareness and protection in this regard, and as citizens we have no choice but to accept what the government and ISPs tell us they are doing to protect our privacy.

This is simply not good enough. The burden of proof of measures taken to ensure customer privacy and non-discriminatory network management lies with ISPs, not with consumers. Yet few in Sri Lanka are looking at what is called network neutrality. Overbroad definitions of national security prevent any real scrutiny of censorship and more disturbingly, espionage by ISPs through technical means. The fact that several e-mail accounts of leading local and international human rights activists have been hacked into in 2008, as well as some leading independent news websites, suggests a degree of growing awareness among those who wish to curtail democratic dissent that web, internet and mobile phone-based communications are increasingly effective as a means of citizen mobilisation and voter education. These growing and persistent challenges will have to be met with more strategic use of ICTs by civil society in future.

\section{Final thoughts}

This discussion on the potential of new media to transform policies and practices of illiberal democracy is not, as of yet, one that has traction among large numbers of people in Sri Lanka. Millions still live without any awareness of the internet or its potential for social change. There are arguably more pressing social issues in some regions than the digital divide - including the ravages of conflict. However, the terrains of violence and conflict also hold within them the possibilities of democratic dialogue mediated through the internet, the web and increasingly mobile phones. Three ideas, among many others, that can help capture the potential of new media are: 
- Creating new media-based initiatives that amplify community aspirations for peace, while at the same time are sensitive to the fragile and complex web of socio-political relations in the context of ongoing peace processes

- Expanding a community's social and knowledge capital through enhanced access to the internet through mobile phones, while eschewing the facile notion that access to internet-based information itself is indicative of community empowerment

- Using the internet and web to devise communities of practice that transform information to trusted and verifiable knowledge that aids conflict transformation within and between communities.

\section{Notes}

All websites cited were accessed 13 January 2009.

1 www.thesundayleader.lk/20090111/ editorial-.htm

2 Santiago Dreaming, www.guardian.co.uk/ technology/2003/sep/08/sciencenews.chile

3 Operation Vula: ICT vs Apartheid, http://fl3tch3r.wordpress.com/2008/04/02/ operation-vula-ict-vs-apartheid

4 Defeating Repressive Regimes, http://ict4peace.wordpress.com/2006/05/10/ defeating-repressive-regimes

5 Dictatorships Catching up with Web 2.0, www.news.com/2010-1028_3-6155582.html? part $=$ rss\&tag $=2547-1 \_3-0-20 \&$ subj $=$ news

6 Why Egypt is Cracking Down on Bloggers, www.time.com/time/world/article/0,8599,1199 896,00.html

7 Myanmar's Sad Lesson - Internet Censorship Still Rules, http://ict4peace.wordpress.com/2007/ 10/05/myanmars-sad-lesson-internetcensorship-still-rules

8 Blogging the Coup, www.cjr.org/short_takes/ blogging_the_coup_1.php

9 Mapping Iran's Online Public: Politics and Culture in the Persian Blogosphere, http://cyber.law.harvard.edu/publications/ 2008/Mapping_Irans_Online_Public

10 Endangered: Our right to 'shoot' in public, www.groundviews.org/2008/02/14/endangeredour-right-to-shoot-in-public

11 www.eyesondarfur.org

12 Political Texting: SMS and Elections, www.thefeaturearchives.com/topic/Culture/ Political_Texting_SMS_and_Elections.html
Animating the potential of new media and the internet is the responsibility of a vibrant democracy. A vibrant democracy in turn is nourished by a culture of open discussion on core issues of governance by all people, in all regions of a country. This symbiosis between democracy and dialogue, between new media and its influence on progressive social policy, between the promise of the internet and web to empower communities and the appropriation of ICT by communities to strengthen their engagement with justice and peace, will be a qualitative and quantitative measurement of the health of democracy in Sri Lanka.

13 Kubatana Reaches out with FrontlineSMS in Zimbabwe, www.blogspot.kiwanja.net/ 2008/04/kubatana-reaches-out-withfrontlinesms.html

14 Kenya in crisis, http://news.bbc.co.uk/2/hi/ technology/6241603.stm

15 New Political Tool: Text Messaging, www.usatoday.com/tech/news/2005-06-30politics-text-tool_x.htm?csp $=34$

16 www.boingboing.net/2004/12/27/ smses_from_sri_lanka.html [and] www.boingboing.net/2005/01/01/nyt_sms_as warning_s.html

17 www.lirneasia.net/2007/08/another-instanceof-voice-failing-and-sms-triumphing-duringdisasters

18 www.lirneasia.net/2005/01/sms-as-part-ofearly-warning-system (and also the interesting comments that follow the original post).

19 www.textually.org/textually/archives/2005/ 01/006698.htm

20 http://globalvoicesonline.org/-/human-rightsvideo

21 www.asiamedia.ucla.edu/article.asp? parentid $=21285$

22 http://ict4peace.wordpress.com/2006/12/07/ new-media-in-cycles-of-violence-usingtechnology-for-new-voices

23 http://ict4peace.wordpress.com/2007/04/12/ darfur-through-google-earth-the-reality-ofconflict-through-crisis-in-darfur

$24 \mathrm{http}: / /$ deaned.blogspot.com

25 www.indi.ca

$26 \mathrm{http}: / /$ dinidudealwis.com

27 http://beyondborders.wordpress.com 
$28 \mathrm{http}: / /$ inmutiny.wordpress.com

$29 \mathrm{http}: / /$ bandaragama.wordpress.com

$30 \mathrm{http}: / /$ caffeinaholic.blogspot.com

$31 \mathrm{http}: / /$ landlikenoother.blogspot.com/2006/ 07/top-10-extremist-of-sri-lanka.html

32 http://transcurrents.com/tamiliana

33 http://electra.blogsome.com

34 The content on Groundviews in English is complemented by content on other citizen journalism initiatives instigated by CPA. Videos on CPA's Vikalpa YouTube Video Channel (www.youtube.com/vikalpasl) have been viewed tens of thousands of times. Vikalpa Video was the first and only example in Sri Lanka of using short videos filmed with a mobile phone being distributed through the web providing alternative perspectives on war, peace and governance. Some of these videos have highlighted the ground situation in the embattled North and East of Sri Lanka, a rarity even for mainstream media (e.g. www.youtube.com/watch? $=$ YwmjYWT0rRU). These videos complement original writing in the vernacular on the Vikalpa website (www.vikalpa.org), Sri Lanka's only Sinhala and Tamil citizen journalism website that now registers over 200 pageviews a day. Voices of Reconciliation Radio (http://radio.voicesofpeace.lk), Sri Lanka's only pod-casting aggregation site archives over 400 hours of mostly vernacular pod-casts, including voices from the embattled North and East.

35 Groundviews in November 2008 completely revamped its comments architecture and at the time of writing, features the most sophisticated and secure platform for comments on any blog in Sri Lanka. Using a plug-in for Wordpress (a blogging platform that Groundviews runs on) called

IntenseDebate, commentators can choose to be anonymous or create an online identity, which cannot be traced back to them, that allows them to securely engage with the content on the site.

36 Disclosure: The author is the Editor of Groundviewes and is solely responsible for the site's content management, technical upgrades and maintenance, marketing and development.

37 For full guidelines see: www.groundviews.org/ submission-guidelines

38 www.citmedia.org/principles

39 www.macworld.com/news/2007/03/06/ franceban/index.php?lsrc $=$ mwrss

40 http://ict4peace.wordpress.com/2008/11/ 13/censored-forum-theatre-on-freedom-ofexpression-at-a-time-of-war

41 http://freemediasrilanka.wordpress.com/ 2008/11/15/supreme-court's-grant-of-leave-toproceed-and-interim-relief-in-challenges-tonew-television-regulations

42 For a deeper analysis of this issue see: http://ict4peace.wordpress.com/2008/11/ 16/gagging-the-web-and-internetimplications-of-the-proposed-private-tvbroadcasting-regulations-in-sri-lanka/

43 These points are dealt with in an expanded form in Journalism of the Future? Problems and Challenges, http://ict4peace.wordpress.com/ 2008/09/15/journalism-of-the-futureproblems-and-challenges

44 A recent case involving Google unmasking the identity of a blogger in India is interesting in this regard. See: http://ict4peace.wordpress.com/ 2008/08/17/unmasking-bloggers-in-indiaraises-some-interesting-questions 